Gynäkol Geburtshilfliche Rundsch 1996;36:234

\title{
Sachregister Vol. 36, 1996
}

Alter $>80$ Jahre 63

Antike geburtshilfliche Lehre 92

Beckenendlage 69

Chemosensibilitätstestung 3 Chemotherapie 3

Chíamydia-trachomatis-lníeküoncn 143 Chlamydiennachweisverfahren 143 Cooley-Anämie 29

Eileiterschwangerschaft 133 Eltern-Kind-Beziehung 149 Endometriumbeurteilung, sonographische

21 Endometriumkarzinom 9, 14 Endoskopie 118

Endoskopische Kolposuspension 75 Episiotomie 159 Extrauteringravidität, Diagnostik 138

Fehlbildungsregister 169

Fertilität, Eileiterschwangerschaft 138

Fetale Stammzellen 105

Therapie 105

Transplantation 105

Fetaler Folgezustand (Fetal outcome) 69 Fettzelltumoren 90 FIGO 198542

- 199442

Fortgeschrittenes Ovarialkarzinom 3 Funktionelle Säuglingssymptome 149

Gebärstuhl 92 Geburtserleben 149 Geburtshocker 69 Geburtskomplikationen 197 Geriatrie 63

Gerichtliche Geburtshilfe 159 GnRH-Analoga 118 Gradeinteilung, postmenopausales Endo-

metrium 21

Gynäkologische Behandlung, Alter 63 - Onkologie 37

Hämoglobinopathie 29 Handschriftenillustration 92 Harnblasenfisteln 197 Herba Coriandrum 92

Histogenese 90

Histologie, Endometriumdicke 21 Hormonmangel 83 Hormonsubstitutionstherapie 83

Hysterektomie 156 Hysteroskopie 9

Immunhistochemie 40

Interferon 44

Intraoperative Komplikation 159

Kaiserschnittrate 69

Karl Schroder 163

Ki-67 156

Klinische Geburtshilfe, Geschichte 163

Kunstgeschichte 92

Laparoskopische Adnexektomie 79 Leiomyom, proliferierend 156 Liposarkom 90

Lokalmedikamentöse Therapie 133

Magische Rezepte 92 Medikamentöse Behandlung, Extrauteringravidität 138 Menopause 101

Mikroinvasives Karzinom der Zervix 42 Mittelalterliche geburtshilfliche Lehre 92 Myome 118

Operative Therapie, Extrauteringravidität

138 Organerhalt 118 Ovarialkarzinom 44 
p53-Protein 40 Proliferationsmarker 133 Protein 90K 44 Psychosomatische Geburtshilfe 149

Reklassifikation 42

Retroperitoneale Lymphadenektomie 3

- Technik 79

Scheidenfisteln 197 Schwangerschaftskomplikationen, infek-

tiöse 143 Screening, Endometriumkarzinom 14 Sensitivität 143 Sexualität 101 Sexualstörungen 83 Spezifität 143 Stadium lal, Ia2 42 Stressinkontinenz 75

ß-Thalassämie 29 Thromboembolieprophylaxe 37 Thromboembolische Komplikationen 37

Transdermales System (Estraderm) 83 Triple-Test 169

Trisomie 21 , pränatale Diagnose 169 Trophoblastlokalisation 133 Tumordebulking 3

Tumorimmunologie 44

Universität Erlangen, Geburtshilfe 163 Urodynamik 75 Uterus 90

Vaginalsonographie 9, 14 Vertikale Gebärstellung 69 Vulvakarzinom 40

Zustand nach Hysterektomie 79

KAIUiER

E-Mail karger@karger.ch Fax+41 613061234 http://www. karger. ch

(C) 1996 S.KargerAG, Basel 